Case Report

\title{
Prenatal Diagnosis of Cantrell's Pentalogy Associated with Agenesis of Left Limb in a Twin Pregnancy
}

\author{
Yigit Cakiroglu, Emek Doger, Sule Yildirim Kopuk, \\ Kadir Babaoglu, Eray Caliskan, and Gulseren Yucesoy \\ Department of Obstetrics and Gynecology, Kocaeli University School of Medicine, Umuttepe Kampusu, Kocaeli, Turkey \\ Correspondence should be addressed to Sule Yildirim Kopuk; suleyildirim@msn.com
}

Received 8 December 2013; Accepted 12 February 2014; Published 23 March 2014

Academic Editors: M. K. Hoffman, P. McGovern, and M. A. Osmanagaoglu

Copyright (c) 2014 Yigit Cakiroglu et al. This is an open access article distributed under the Creative Commons Attribution License, which permits unrestricted use, distribution, and reproduction in any medium, provided the original work is properly cited.

\begin{abstract}
Pentalogy of Cantrell is a rare malformation described in the literature. We report a case of pentalogy of Cantrell associated with left limb deficiency in a twin pregnancy. The fetus with multiple anomalies revealed kyphosis, ectopia cordis, and a large defect with protruding liver and bowel loops at 12 weeks and 3 days of gestational age on ultrasound scan. The other fetus was ultrasonographically normal. We diagnosed a case of pentalogy of Cantrell in a twin pregnancy after exclusion of limb body wall complex, body stalk anomaly, and amniotic band syndrome and after delivery of the fetuses. Macroscopic examinations were ectopia cordis, extrusion of the abdominal organs without membranes surrounding, and agenesis of the left limb.
\end{abstract}

\section{Introduction}

Many cases of pentalogy of Cantrell (PC) have been reported since the first case which was defined by Cantrell and colleagues in 1958 [1]. The initial syndrome was diagnosed as a pentad including midline supraumbilical abdominal wall defects, deficiency of the anterior diaphragm, defects of the lower sternum, defects of the diaphragmatic pericardium, and congenital intracardiac abnormalities. Variable cardiac anomalies have been reported and among the anomalies, ventricular septal defects, atrial septal defects, or other abnormalities are the most common reported.

We have reviewed the published literature on PC and reported a twin case with the diagnosis of PC and a normal fetus.

\section{Case Report}

A 20 -year-old gravida 1, para 0 , abortus 0 pregnant woman was admitted to our perinatology unit with the suspicion of ectopia cordis in a twin pregnancy at the 12th week of gestation.

She was performed transvaginal ultrasound scan and the scan revealed a dichorionic-diamniotic twin pregnancy.
Crown-rump lengths were $48 \mathrm{~mm}$ and $46 \mathrm{~mm}$ corresponding to $11+5$ weeks and nuchal translucencies were 1.2 and $1.6 \mathrm{~mm}$, respectively. Ultrasound scan of the first twin revealed ectopia cordis and a large defect with protruding liver and bowel loops (Figure 1). The second twin was ultrasonographically normal. The diagnosis of PC was suspected after exclusion of limb body wall complex (LBWC), amniotic band syndrome, and body stalk anomaly. The parents were informed about the syndrome and the prognosis and were offered selective feticide procedure. They chose to continue the pregnancy without any intervention. A 1-3 apgared 1000 gr female fetus and a 7-8 apgared 2500 gr male fetus were born by a cesarean section at 37 weeks of gestation. The macroscopic observations were ectopia cordis, extrusion of the abdominal organs without membranes surrounding, hypoplastic ribs, sternum, and agenesis of the left limb (Figure 2). The second twin was macroscopically normal without any malformations. The family refused an autopsy procedure.

\section{Discussion}

Pentalogy of Cantrell is a rare syndrome with an estimated incidence of 5.5 per 1 million live births [2]. The etiology has not been fully determined but the most accepted hypothesis 


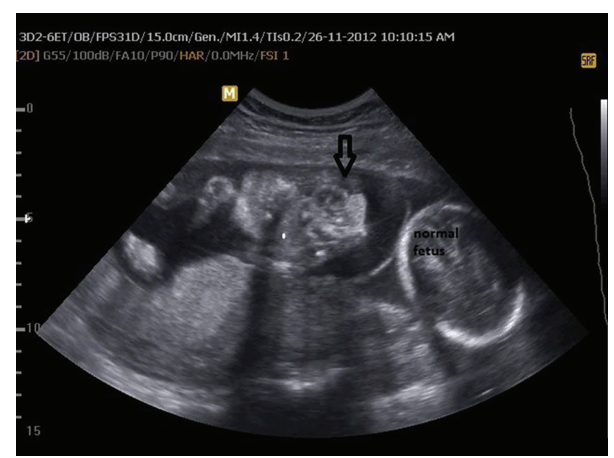

FIGURE 1: Ultrasonographic view of twins at 23 weeks of gestational age; arrow indicated heart protruding out of the sternal defect.

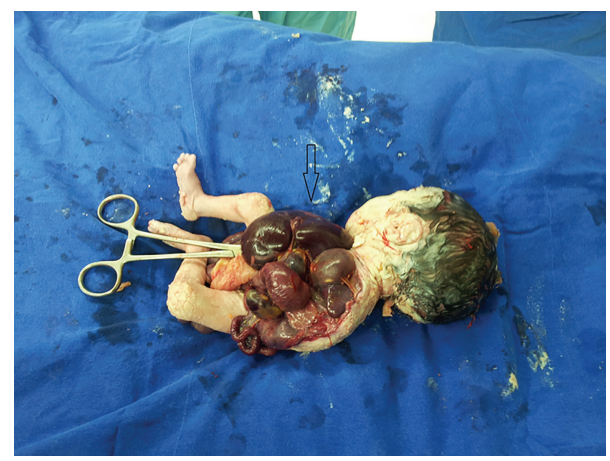

FIGURE 2: Postmortem photo of case showed large omphalocele with evisceration of all the gastrointestinal organs with absent sternum and rib cage and left upper limb are not shown.

is developmental failure of a segment of the lateral mesoderm at around 14-18 days of embryonic life [1]. The full spectrum consists of midline supraumbilical abdominal wall defects, deficiency of the anterior diaphragm, defects of the lower sternum, defects of the diaphragmatic pericardium, and congenital intracardiac anomalies.

Various intracardiac anomalies have been described in the PC including ventricular septal defects (VSD) (100\%), atrial septal defects (ASD) (53\%), tetralogy of Fallot (TOF) $(20 \%)$, pulmonary stenosis $(33 \%)$, and left ventricular diverticulum (20\%), whereas Vazquez-Jimenez et al. have reported that VSD is not consistent in every case $(72 \%)[1,3]$. Likewise, VSD was not diagnosed in our case. Also, craniofacial and central nervous system anomalies, limb defects such as clubfoot, tibia, and radius agenesis, hypodactyly, and hypoplasia are the other associated anomalies $[4,5]$.

$\mathrm{PC}$ is a syndrome characterized by a distinct phenotypic variability. Toyama suggested three classes of PC: class 1: complete form, all five defects are present; Class 2: probable diagnosis that four defects are present, including intracardiac and ventral wall abnormalities; and class 3: incomplete expression, always including sternal abnormality with various combinations of defects [6]. Class 1-complete form of PChas the worst prognosis and intracardiac defects which do not influence prognosis [7]. However, Grethel et al. have reported a case report with severe intracardiac malformations that has poor prognosis [8].
Abdominal wall defects that are seen in PC are omphalocele, diastasis recti, epigastric hernia, umblical hernia, and combined defects. Sternal malformations that can be seen in PC include bifid sternum, absent xiphoid process, short sternum, and defective formation of lower third [9]. Differential diagnosis of midline defects includes PC, LBWC, body stalk anomaly, and amniotic band syndrome.

We have reviewed the published literature on $\mathrm{PC}$ and reported a twin case with the diagnosis of $\mathrm{PC}$ and a normal fetus. Uygur et al. and Chen et al. have reported two cases with pentalogy of Cantrell and limb defects $[4,10]$. Chen et al. reported a twin case with one of the fetuses having concomitant anencephaly and left upper limb hypoplasia [11].

$\mathrm{PC}$ is a syndrome with high mortality rate and the survival rate is lower than $40 \%$ [12]. The optimal management strategies and prognostic indices for neonates remain to be established. Generally, most of the fetuses associated with ectopia cordis indicate poor prognosis, whereas ectopia cordis in partial association with incomplete presentation of $\mathrm{PC}$ is likely more favorable [13].

In conclusion, early counseling should be made to make differential diagnosis. When the PC is diagnosed, a multidisciplinary team including an obstetrician, a neonatologist, a pediatric cardiologist, a pediatric surgeon, and a genetics specialist should agree on the best approach to PC.

\section{Conflict of Interests}

The authors state that they have no competing interests.

\section{References}

[1] J. R. Cantrell, J. A. Haller, and M. M. Ravitch, "A syndrome of congenital defects involving the abdominal wall, sternum, diaphragm, pericardium, and heart," Surgery, Gynecology \& Obstetrics, vol. 107, no. 5, pp. 602-614, 1958.

[2] R. Carmi and J. A. Boughman, "Pentalogy of Cantrell and associated midline anomalies: a possible ventral midline developmental field," American Journal of Medical Genetics, vol. 42, no. 1, pp. 90-95, 1992.

[3] J. F. Vazquez-Jimenez, E. G. Muehler, S. Daebritz et al., "Cantrell's syndrome: a challenge to the surgeon," Annals of Thoracic Surgery, vol. 65, no. 4, pp. 1178-1185, 1998.

[4] D. Uygur, S. Kş, E. Şener, S. Günçe, and N. Semerci, "An infant with pentalogy of Cantrell and limb defects diagnosed prenatally," Clinical Dysmorphology, vol. 13, no. 1, pp. 57-58, 2004.

[5] E. K. Pivnick, R. A. Kaufman, G. V. Velagaleti, W. M. Gunther, and D. Abramovici, "Infant with midline thoracoabdominal schisis and limb defects," Teratology, vol. 58, no. 5, pp. 205-208, 1998.

[6] W. M. Toyama, "Combined congenital defects of the anterior abdominal wall, sternum, diaphragm, pericardium, and heart: a case report and review of the syndrome," Pediatrics, vol. 50, no. 5, pp. 778-792, 1972.

[7] J. H. van Hoorn, R. M. Moonen, C. J. Huysentruyt, L. W. Van Heurn, J. P. Offermans, and A. L. M. Mulder, "Pentalogy of Cantrell: two patients and a review to determine prognostic factors for optimal approach," European Journal of Pediatrics, vol. 167, no. 1, pp. 29-35, 2008. 
[8] E. J. Grethel, L. K. Hornberger, and D. L. Farmer, "Prenatal and postnatal management of a patient with pentalogy of Cantrell and left ventricular aneurysm," Fetal Diagnosis and Therapy, vol. 22, no. 4, pp. 269-273, 2007.

[9] N. Singh, M. L. Bera, M. S. Sachdev, N. Aggarwal, R. Joshi, and V. Kohli, "Pentalogy of cantrell with left ventricular diverticulum: a case report and review of literature," Congenital Heart Disease, vol. 5, no. 5, pp. 454-457, 2010.

[10] C.-P. Chen, C.-Y. Hsu, C.-Y. Tzen, S.-R. Chern, and W. Wang, "Prenatal diagnosis of pentalogy of Cantrell associated with hypoplasia of the right upper limb and ectrodactyly," Prenatal Diagnosis, vol. 27, no. 1, pp. 86-87, 2007.

[11] C.-P. Chen, C.-Y. Tzen, C.-Y. Chen, F.-J. Tsai, and W. Wang, "Concomitant exencephaly and limb defects associated with pentalogy of Cantrell," Taiwanese Journal of Obstetrics and Gynecology, vol. 47, no. 4, pp. 476-477, 2008.

[12] C. S. O'Gorman, T. A. Tortoriello, and C. J. McMahon, "Outcome of children with pentalogy of Cantrell following cardiac surgery," Pediatric Cardiology, vol. 30, no. 4, pp. 426-430, 2009.

[13] K. K. Mallula, C. Sosnowski, and S. Awad, "Spectrum of Cantrell's pentalogy: case series from a single tertiary care center and review of the literature," Pediatric Cardiology, vol. 34, no. 7, pp. 1703-1710, 2013. 


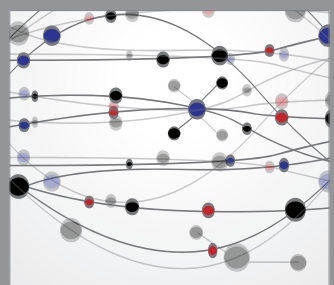

The Scientific World Journal
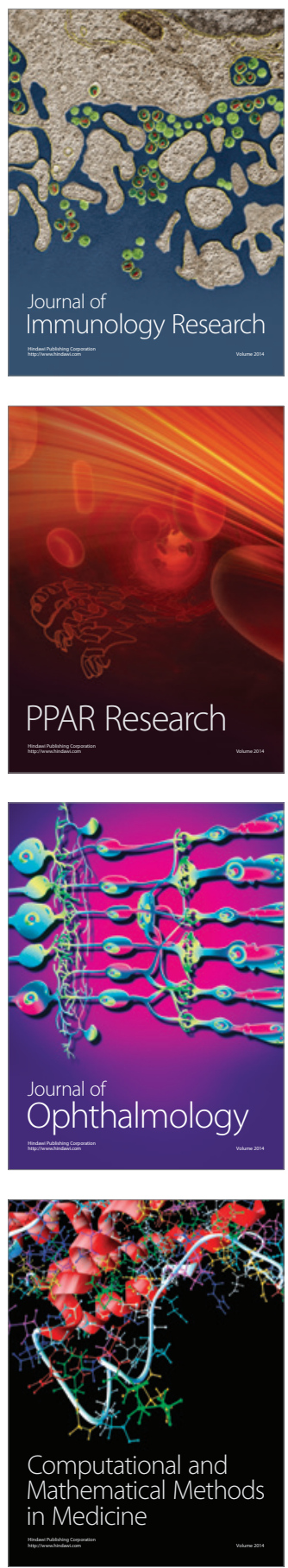

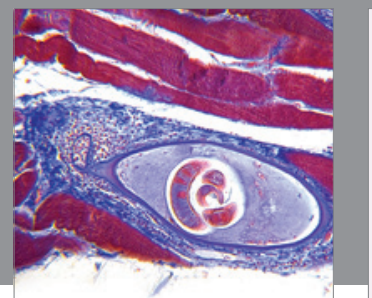

Gastroenterology

Research and Practice
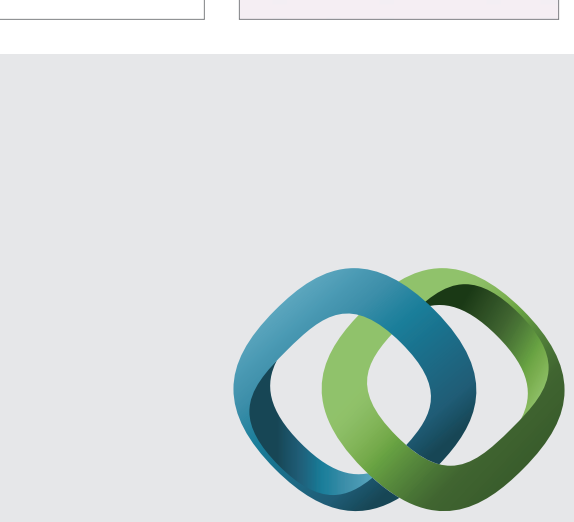

\section{Hindawi}

Submit your manuscripts at

http://www.hindawi.com
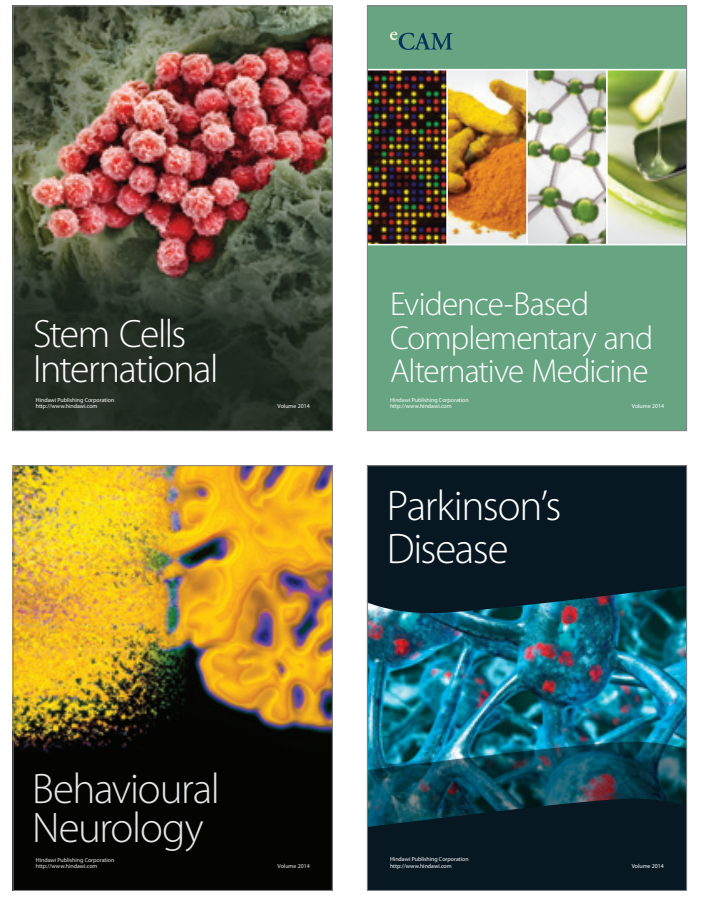
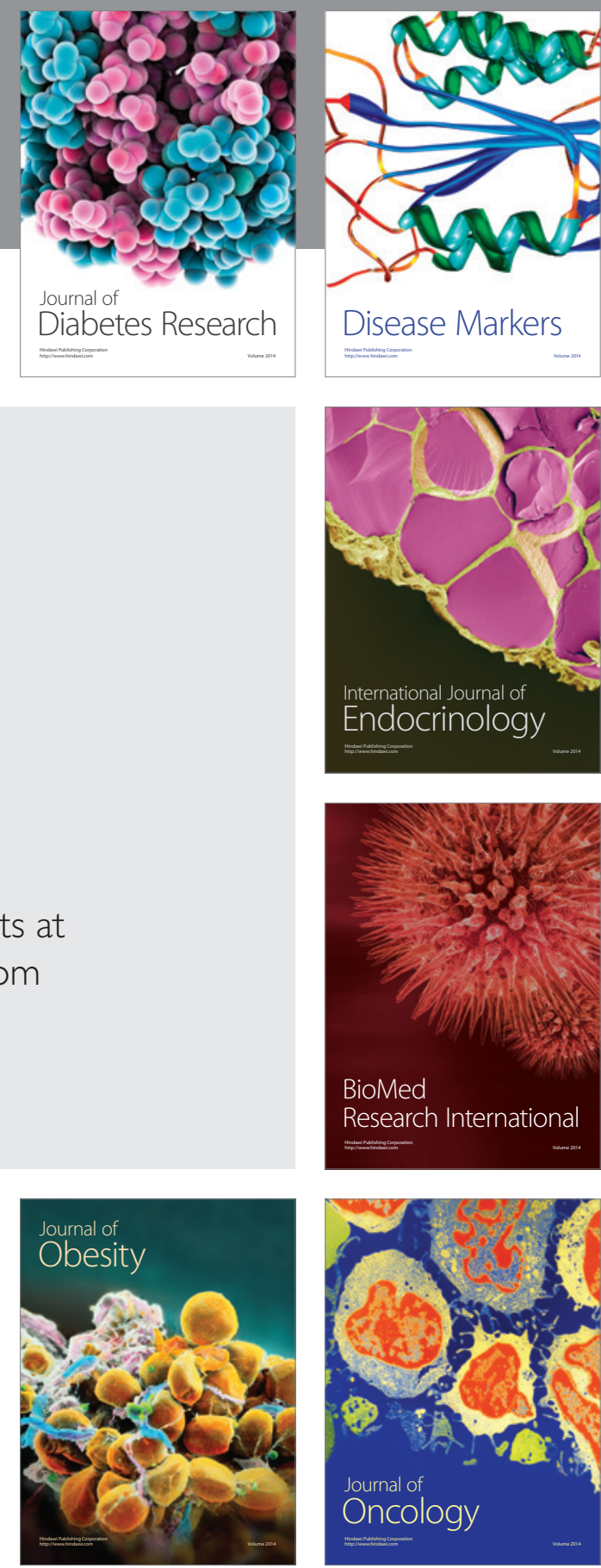

Disease Markers
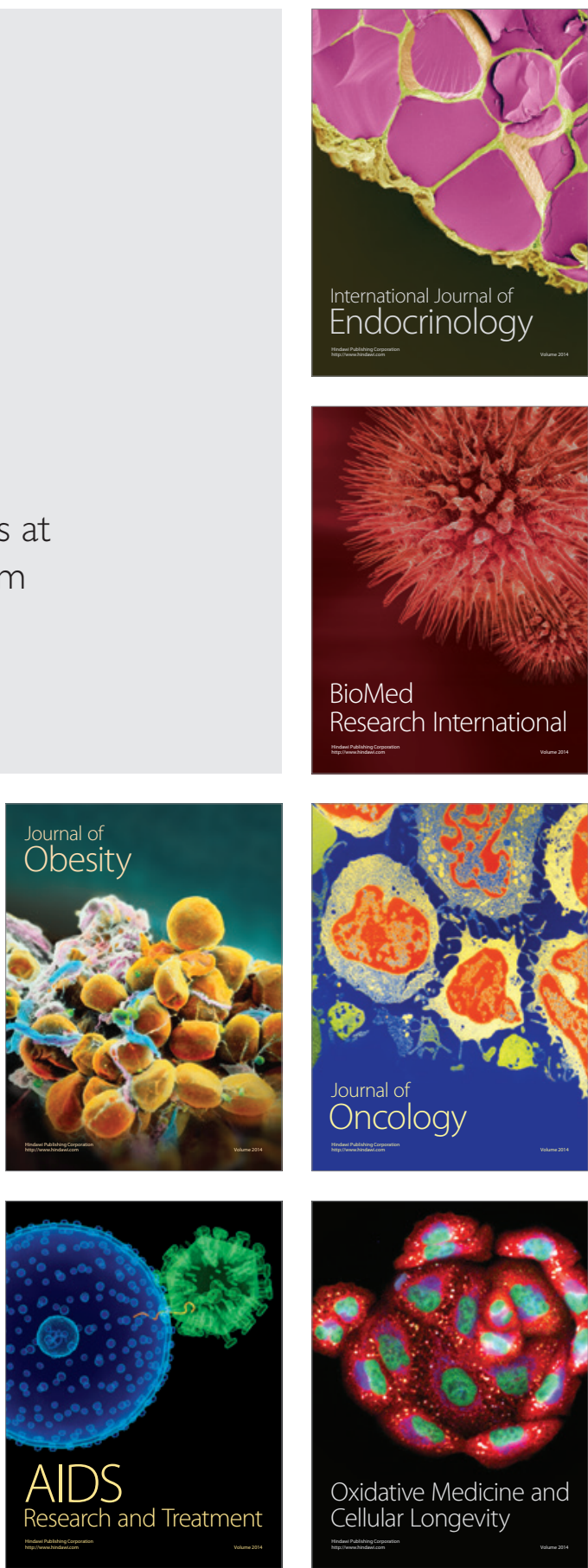